\title{
Analysis of Different Meta Heuristics Method in Intelligent Fault Detection of Multilevel Inverter with Photovoltaic Power Generation Source
}

\author{
T.G. Manjunath ${ }^{1}$, Ashok Kusagur ${ }^{2}$ \\ ${ }^{1}$ Department of Electrical and Electronics Engineering, Sai Vidya Institute of Technology, Bangalore, India \\ ${ }^{2}$ Department of Electrical and Electronics Engineering, UBDT College of Engineering, Davanagere, India
}

\begin{tabular}{l} 
Article Info \\
\hline Article history: \\
Received Apr 27, 2018 \\
Revised Jul 20, 2018 \\
Accepted Aug 6, 2018 \\
\hline
\end{tabular}

Keyword:

Fault diagnosis of multilevel

Hardware feasibility

Inverter

Meta heuristic algorithm

Parameter optimization

\begin{abstract}
Meta Heuristic methods have made a deep impact in the area of optimization in different streams of engineering. The performance of these algorithms is of importance because the hardware implementation of these algorithms is to be carried out for different engineering applications. As an important application in High Voltage DC (HVDC) transmission and Industrial Drives the multilevel inverter fault diagnosis is carried out using the different metaheuristic methods with Neural Network as the decision making algorithm. The optimization of the weight and the bias values in the neural network diagnosis system is carried out in order to analyze the performance by means of comparing the Mean Square Error (MSE) while the Neural Network is getting trained for different fault conditions in the multilevel inverter. Matlab based implementation is carried out and the results are tabulated and inferred for a Multilevel Inverter fed from the Photovoltaic power generation system. In order to increase the robustness of the fault detection, with renewable energy based power generation system as the source for the Multilevel Inverter, the feature extracted from the multilevel inverter are positive, negative and zero sequence voltage along with the THD of the output voltage. The optimization algorithm used is Particle Swarm Optimization (PSO), Cuckoo Search Algorithm(CSA), Genetic Algorithm(GA) and Tabu Search Algorithm (TSA)
\end{abstract}

Copyright $\odot 2018$ Institute of Advanced Engineering and Science. All rights reserved.

\section{Corresponding Author:}

T.G Manjunath,

Department of Electrical and Electronics Engineering,

Sai Vidya Institute of Technology, Bangalore, India

Email: tgmnath@gmail.com

\section{INTRODUCTION}

The The usage of multilevel inverter is expanding day by day as the HVDC and the Industrial Drives need performance enhancement in the quality of power that has to be delivered to the industry and the transmission systems.Cascaded $\mathrm{H}$ bridge being the advanced multilevel inverter topology,many literatures are using the Cascaded topology. Optimized Artificial Neural Network based implementation for fault detection of multilevel inverter is carried out in [1-3].Investigation of different fault mode behavior is carried out for different types of faults [4]. The park's transform vector pattern is used for the fault diagnosis in the voltage source inverter fed AC drives [5][6]. The classification of the fault wasdependent on the load characteristics as current is considered for fault detection. The different fault detection methods are reviewed [7], voltage histogram based fault detection is carried out in [8-9].The wavelet analysis of the output voltages and input DC currents for fault diagnosis is carried out in [10-11].Since the current waveform would be a problem when large variation in the loads would lead to misinterpretation the wavelet analysis based fault detection is carried out [12]. Output voltage frequency analysis [13], artificial intelligence based fault 
detection and reconfiguration [14-15] are also proposed which are complex to implement. The different meta-heuristic based fault identification and the remedial action are also carried out in literature [17-21]. A time analysis of the zero current occurring while the zero voltage is occurring in a multilevel inverter, which is controlled by the rotating level shifted pulse width modulation is carried out [22]. Probabilistic Neural Network for learning the fault detection using the wavelet as the feature extraction is carried out in [23].This paper attempts to carry out a performance analysis of the different meta- heuristic method on the diagnosis of the open switch fault in the cascaded multilevel inverter. The fault conditions are trained on the ANN with the radial basis function as the learning function. The parameters like the MSE is optimized by the use of the Meta heuristic methods like PSO,GA, TSA and CSA.A robust algorithm for fault detection is a need, as in the previous literature; it is obvious that the fault prediction has created more misinterpretation. Thus the learning based algorithms have to be implemented which would facilitate the robust fault detection. Thus the radial basis function based ANN implementation is chose. The training of the RBF based ANN is carried out by optimizing the training parameters comprising both weight and the bias values in the neural network learning process. This paper which is the improvement of the previous works [1-3] is organized as follows, the Section -II would have the description about the training of the ANN with the radial basis function, Section -III discusses about the optimization algorithm used in the ANN parameter estimation, SectionIVexamines the results and discussion with inference of the different meta heuristic methods, and it is followed by the conclusion and references.

\section{FORMULATION OF PARAMETER ESTIMATION USING META HEURISTIC METHODS}

The formulation of any meta-heuristic method would include the identification of parameter or the independent variables, initial number of population of the variables chosen, objective function, vector function of the meta-heuristic method. The parameters already chosen in the previous section are the weight and the bias value of the radial basis function regression. The Figure 1 depicts the overall implementation of the parameter estimation algorithm that we implement in this paper.

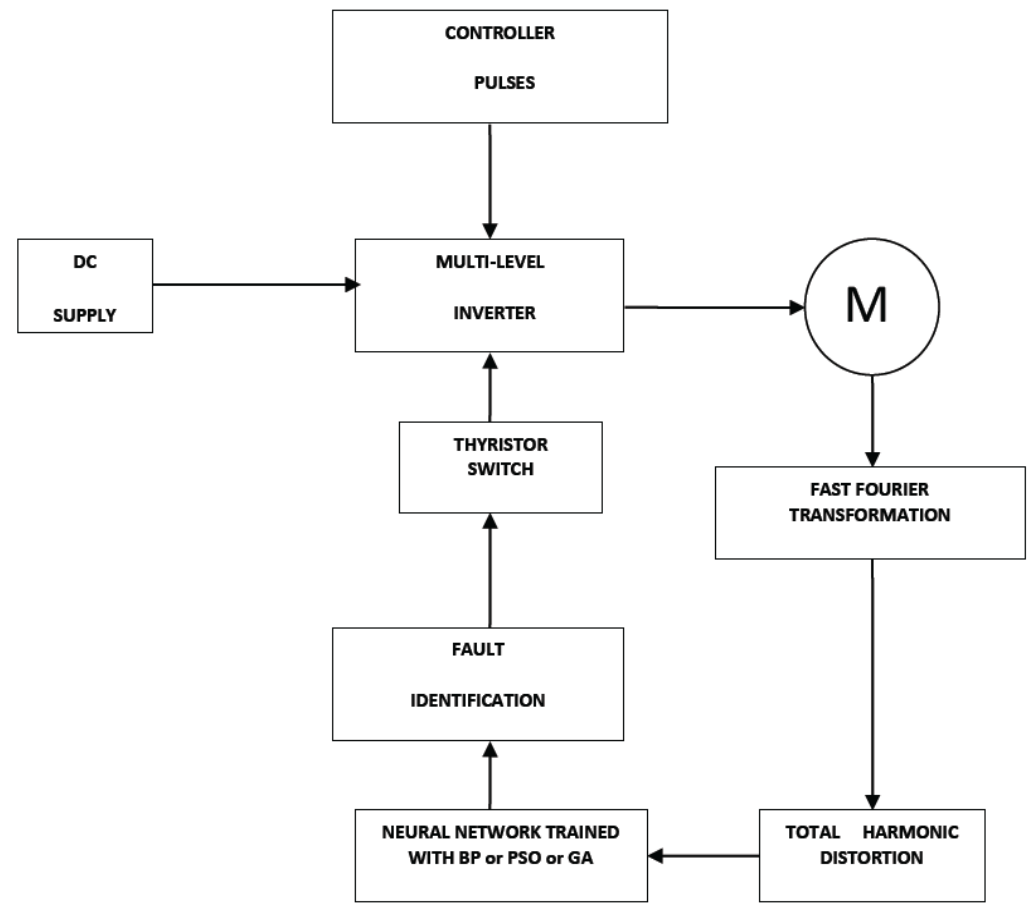

Figure 1. Overall parameter estimation block diagram

The topology of the three phase Cascaded multilevel Inverter is as shown in Figure 2. The objective function is the reduction of the MSE and RMSE during the training of the RBFBANN.The velocity update function of the PSO is 


$$
v_{i}(t+1)=w v_{i}(t)+c_{1} r_{1}\left[\hat{x}_{i}(t)-x_{i}(t)\right]+c_{2} r_{2}\left[g(t)-x_{i}(t)\right]
$$

where $v_{i}(t+1)$ is the new value of the weight or the bias value, $\hat{x}_{i}(t)$ is the best weight or bias value in the current iteration, $c_{1}$ and $c_{2}$ are constants with values near $2, g(t)$ is the weight or bias value which is the global best in all the iteration calculated so far, $w$ is the inertial coefficient which is a constant.

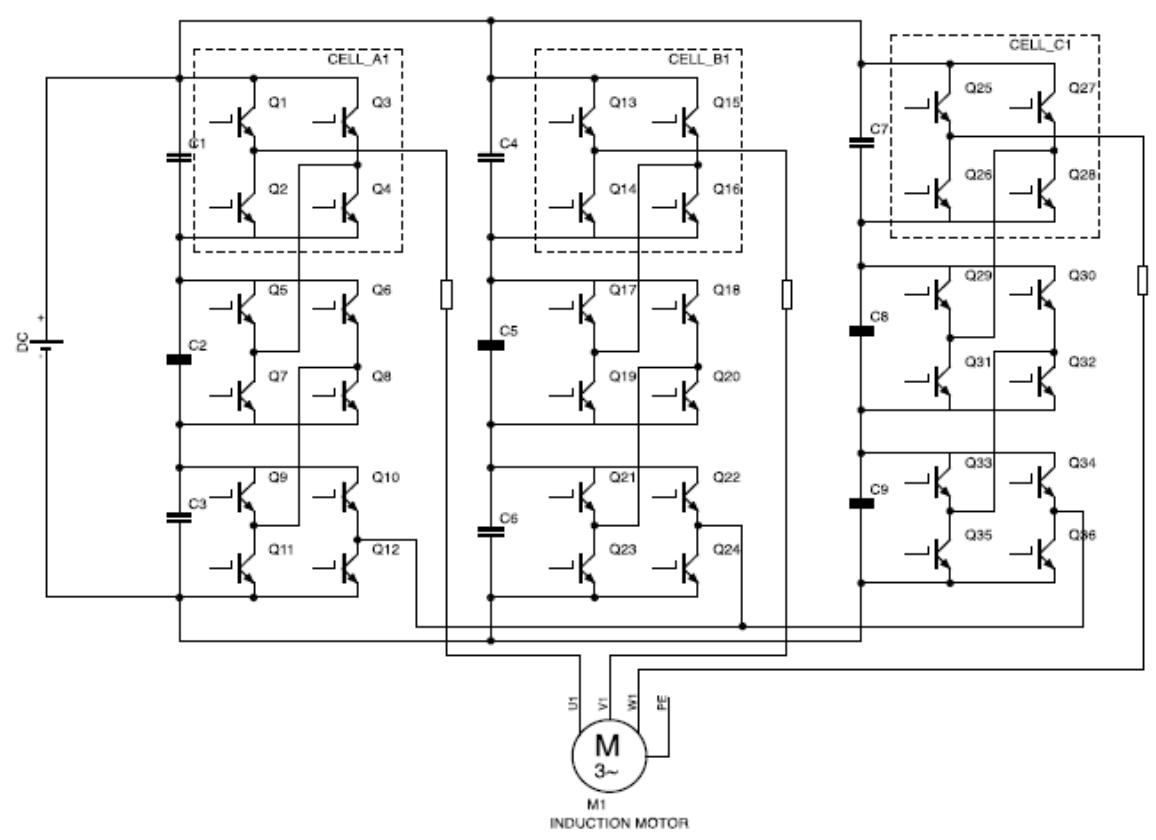

Figure 2. Seven level three phase cascaded multilevel inverter topology

The CSA algorithm is inspired by the way the Cuckoo would act as an intruder to the crow's nest to lay eggs in the crow's nest. The best nest would allow the egg to grow but the worst nest would throw away the eggs. The velocity update function for the CSA algorithm is as given [18], The probability of the host bird to find the intruder egg is $\mathrm{Pa}$. And the new nest can be found by the following formula,

$$
X_{i}(t+1)=X_{i}(t)+\alpha \operatorname{levy}(\lambda)
$$

where $X_{i}(t+1)$ is the possible solutions, $X_{i}(t)$ is the previous solution, $\alpha$ is the step size which controls the amount of search scale, is the number of nest that has to be abandoned in the current iteration. The Cuckoo would lay the eggs by a randomness of the Levy Flight, which is defined by the following function,

$$
\operatorname{levy}(\lambda)=\left|\frac{\Gamma(1+\lambda) \times \sin (\Pi \lambda / 2)}{\Gamma((1+\lambda) / 2) \times \lambda \times 2^{((\lambda-1) / 2)}}\right|^{1 / \lambda}
$$

where is a constant $(1<\quad 3)$ and is the gamma function which is defined by the integral value ,

$$
\Gamma(x)=\int_{0}^{\infty} e^{-t} t^{x-1} d t
$$


as the velocity update function of GA the following process would be calculated.The parent selection for the population generation is carried using the Roulette Selection method as defined below[3],

$$
\begin{aligned}
& S_{i}=\frac{Y_{i}}{\operatorname{Sum}(Y)} \\
& S 1=0 \\
& J=1
\end{aligned}
$$

Where $Y$ is the set of all fitness values, $Y_{i}$ is the ith fitness value. Let $\mathrm{S} 1$ be some random value and $\mathrm{S} 2$ and $J$ are variables. The Roulette selection algorithm can be defined as follows,

While $S 2>S 1$ the following steps has to follow

Find $S 2=S 2+S(J)$

Increment $\mathbf{J}$

End

Once the while loop is becoming false the $J$ value is taken and the population at the $J$ th position is selected as the parent.

The arithmetic crossover is used to create the new offspring from the two parents selected using the Roulette selection. Two off springs are generated using the following formulae,

$$
\begin{aligned}
& \text { Offspring } 1=a * \text { parent } 1+(1 \quad a)^{*} \text { parent } 2 \\
& \text { Offspring } 2=\left(\begin{array}{ll}
1 & a
\end{array}\right) * \text { parent } 1+a * \text { parent } 2
\end{aligned}
$$

Where, a is the random weighting factor. In order to maintain genetic diversity between the off springs the mutation operation is carried out[3]. For the calculation of the mutation the maximum and the minimum weight values are taken from the a values and it is mentioned in the below equations as 'maxweight' and 'minweight'. The mutation operation is defined in the following formulae,

$$
=12 * \text { randnum }
$$

Where, randnum is the random value.

Using the above value the inverse error function is calculated and utilized in the following formulae,

$$
Z=\text { inverseerrorfunction }()^{*} 2^{0.5}
$$

The offspring is calculated by using

Offspring $=Z^{*}+$ parent

$$
=\frac{(\max w e i g h t \quad \min w e i g h t)}{10}
$$

reduces its value for every iteration $=\overline{1.05}$.

The new populated value from the genetic algorithm is used to be applied in the objective function. The updation of the parameter in the TSA would occur by finding the neighbors in the solution space. TSA develops the new solution space using the memory structures using the equation (10)

$$
N_{-} \text {list }(i,:)=\text { sbest }^{*} \operatorname{rand} * S\left(\operatorname{randi}\left(p_{\text {pop }} \text { size, } 1\right),:\right)
$$

The solution space for the new iteration is developed by using the above equation where $N_{\text {_list }}(i,:)$ is all the neighbors that would be used in the next iteration and sbest is the best solution that occurred in the previous iteration and $S$ is the set of all the neighbors which is the memory. This list of new neighbors is called the Tabulist, which is used for finding the solution by evaluating the objective function. The comparison of all the above meta-heuristics based implementation is carried out and the results are tabulated. The comparative analysis of the different methods are analyzed and inferred..By different 
experiments it is come to a conclusion that RBF is a universal approximating function and classifier, thus it happens to be used in this paper.

\section{RESULTS AND ANALYSIS}

The Matlab based implementation is carried out on the 7 level Multilevel inverter and the execution time of the RBFBANN without the optimization, with PSO,GA,TSA and CSA is carried out and the results are tabulated and inferred for the performance analysis of the different methods. The results that are obtained from the basic RBFBANN are as given below for the same kind of graphs would be obtained for all the methods thus not repeated. The Figure 3 depicts the positive voltage sequence that is given as the instantaneous input to the input nodes of the neural network. Similarly Figure 4,5 are the Negative and the zero sequence voltages of the inverter respectively. The Figure 6,7 and 8 are the positive, negative and zero sequence phase respectively of the inverter that is fed to the input nodes of the Neural Network. For the time secs 0 to $0.25 \mathrm{secs}$ and 0.75 to $1 \mathrm{secs}$ there is a phase difference in angle calculation. So these three is taken as another fault classifier input for neural network. The difference is zoomed and shown in the above figure. These are calculated from equation from the results it can be seen that the basic radial function is used to reduce the mean square error (10-29). Therefore RBF is used in neural networks and trained with PSO to reduce the average square error. And that gives a very less error value, around zero. $V_{1}, V_{2} \& V_{0}$ are has real and imaginary value real value is magnitude and imaginary is angle.

Figure 9 is the important graph, which depicts the instantaneous THD value of the inverter at different switch failure. The Figure 9 shows the voltage THD values of Q1, Q2, Q3 and Q4 faulted at each $0.25 \mathrm{sec}$ respectively. So this THD value is given as input and target is used as the switch number 1 to 4 in each $0.25 \mathrm{sec}$. After learning using this faults can be identified and remedial actions can be taken. The comparative analysis of the execution time of the different algorithms with different iteration number is given in Table 1. By using cuckoo search algorithm, the error minimizes to zero consequently more accurate than PSO. So RBF neural network trained with cuckoo search algorithm is performing better comparatively. According to the MSE these algorithms are getting the lowest of all the algorithm is given by the cuckoo search algorithm. The Table 2 shows about the execution time of the Matlab code on the computer system with $8 \mathrm{~GB}$ RAM and $2.4 \mathrm{Ghz}$ Intel i5 processor. The execution time of the CSA algorithm is comparatively less and thus it has the advantage of being implemented on the hardware. Hardware feasibility is more for the CSA algorithm.

$$
\begin{gathered}
v_{1}=\frac{1}{3} *\left(V_{a}+a * V_{b}+a^{2} * V_{c}\right) \\
v_{1}=\frac{1}{3} *\left(V_{a}+a * V_{b}+a^{2} * V_{c}\right) \\
v_{2}=\frac{1}{3} *\left(V_{a}+a^{2} * V_{b}+a * V_{c}\right) \\
=\frac{1}{3} *\left(V_{a}+V_{b}+V_{c}\right) \text { Where, } \\
a=\exp \left(j * 2 * \frac{\pi}{3}\right)
\end{gathered}
$$

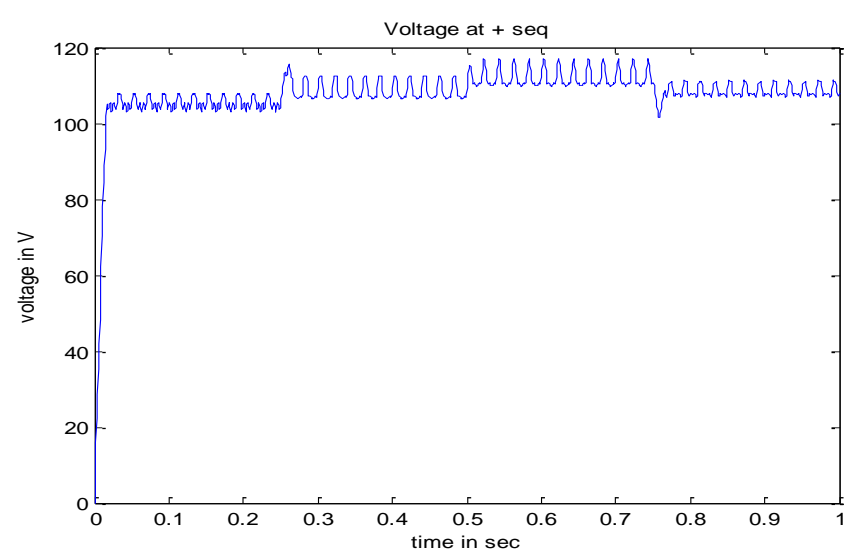

Figure 3. Positive voltage sequence 


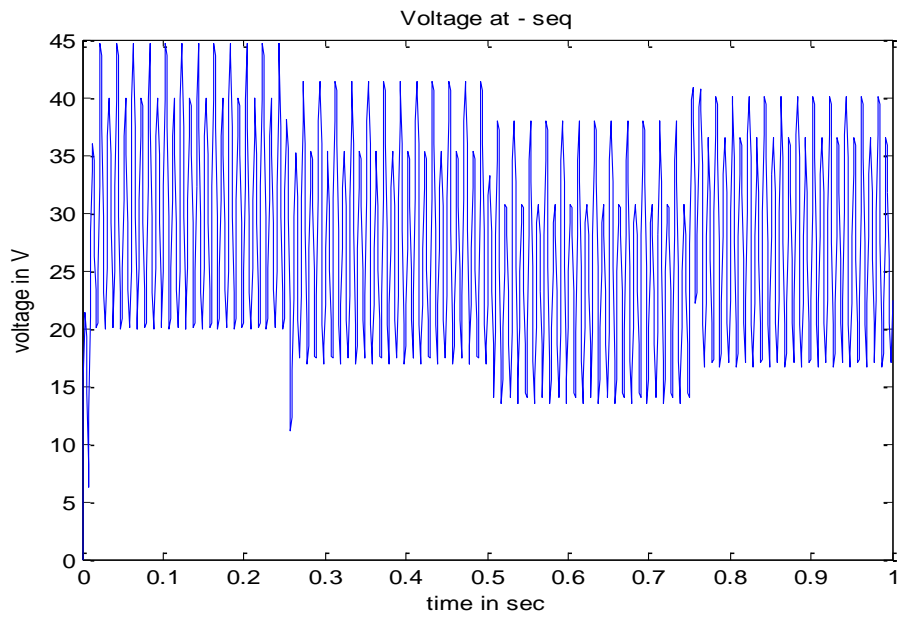

Figure 4. Negative voltage sequence

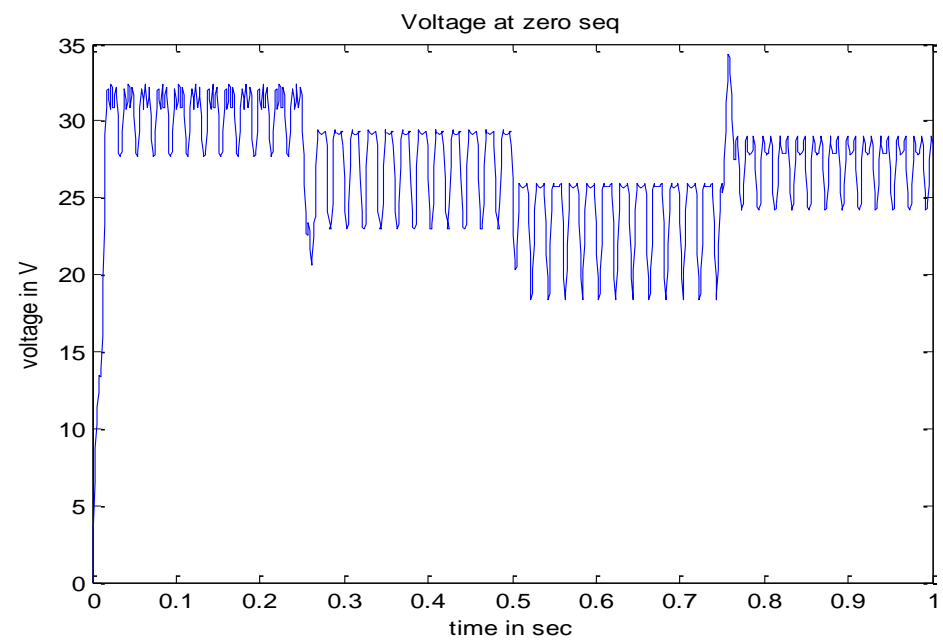

Figure 5. Zero voltage sequence

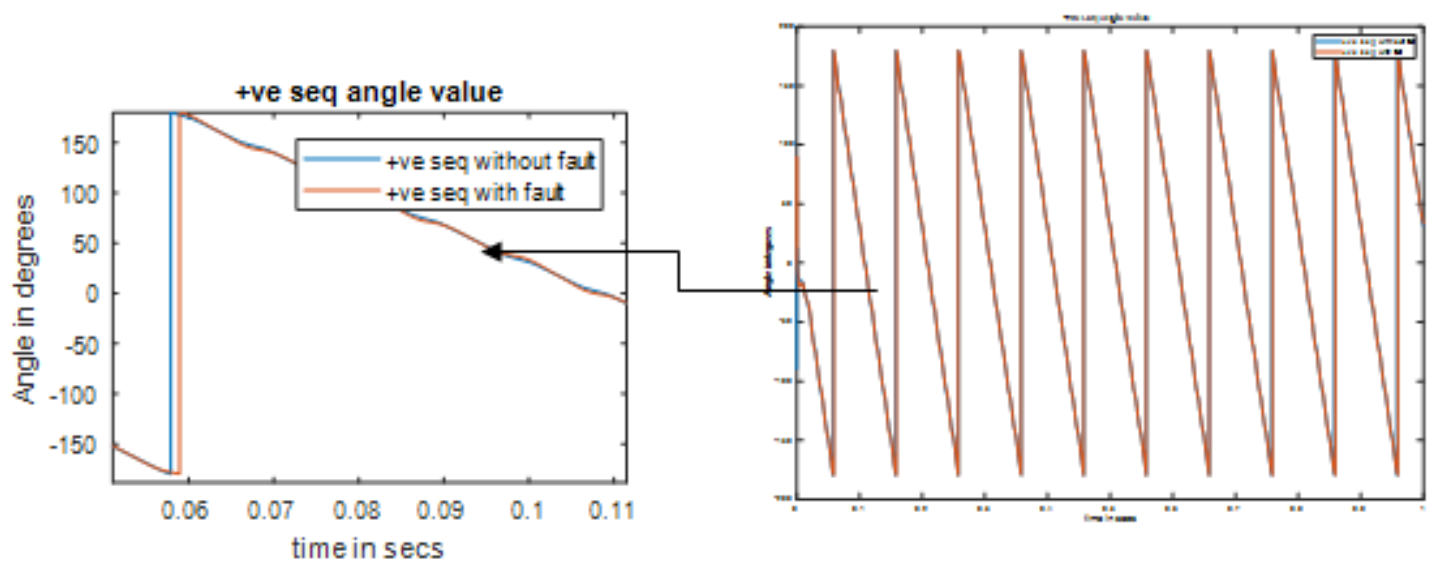

Figure 6. Positive sequence phase with and without fault 


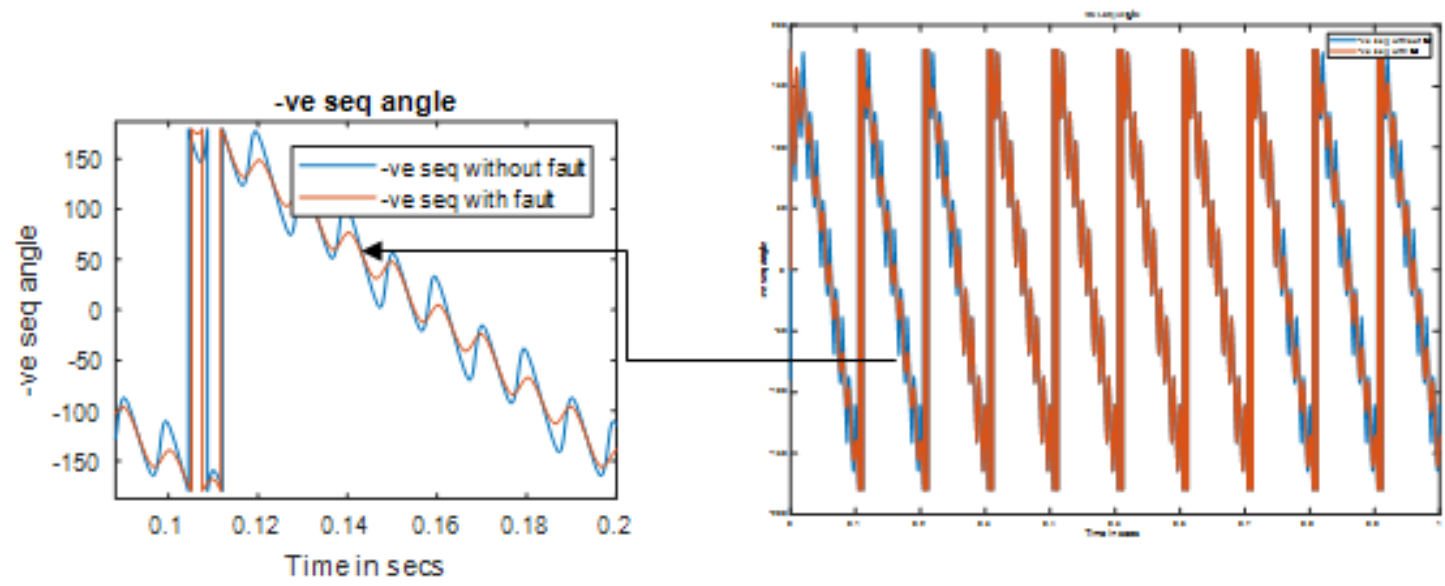

Figure 7. Negative sequence phase with and without fault

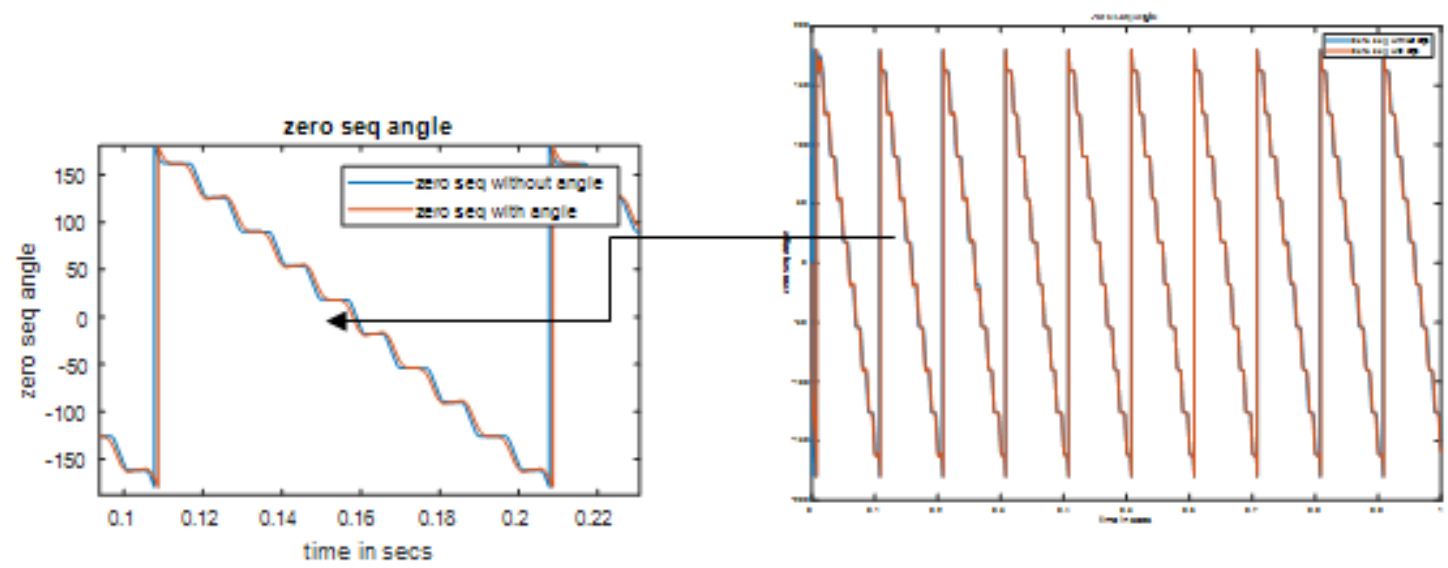

Figure 8. Zero sequence phase with and without fault

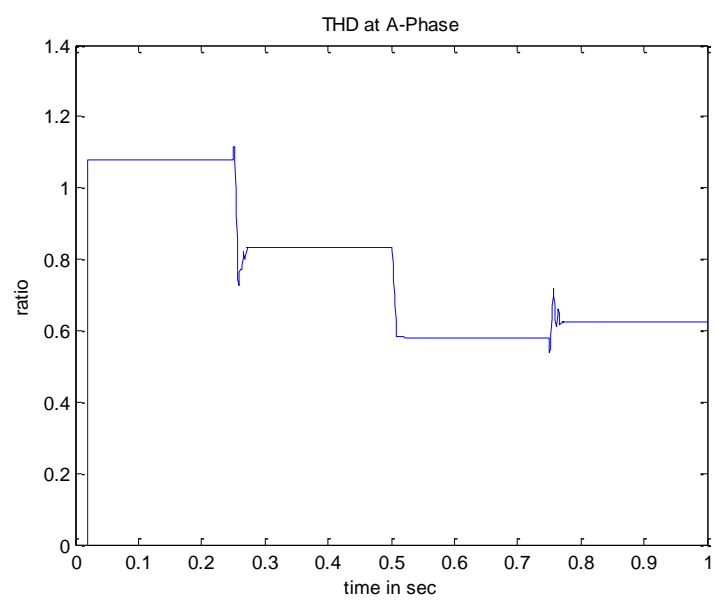

Figure 9. THD A-phase 
Table 1. Mean Square Error Comparison of Neural Network trained with and RBF Neural Network trained with PSO and CSA

\begin{tabular}{lllll}
\hline Run no. & RBF with PSO & RBF with GA & RBF with TSA & RBF with CSA \\
\hline 1 & $2.11 \mathrm{E}-28$ & $2.90 \mathrm{E}-25$ & $6.44 \mathrm{E}-29$ & $6.64 \mathrm{E}-29$ \\
2 & $1.44 \mathrm{E}-28$ & $1.33 \mathrm{E}-25$ & $7.95 \mathrm{E}-29$ & $7.13 \mathrm{E}-29$ \\
3 & $1.03 \mathrm{E}-28$ & $1.23 \mathrm{E}-25$ & $1.87 \mathrm{E}-28$ & $1.47 \mathrm{E}-28$ \\
4 & $1.02 \mathrm{E}-28$ & $1.12 \mathrm{E}-25$ & $6.89 \mathrm{E}-29$ & $6.38 \mathrm{E}-29$ \\
5 & $1.21 \mathrm{E}-28$ & $1.01 \mathrm{E}-25$ & $1.88 \mathrm{E}-28$ & $1.12 \mathrm{E}-28$ \\
6 & $2.11 \mathrm{E}-28$ & $1.00 \mathrm{E}-25$ & $1.88 \mathrm{E}-28$ & $1.13 \mathrm{E}-28$ \\
7 & $7.12 \mathrm{E}-29$ & $3.12 \mathrm{E}-26$ & $8.65 \mathrm{E}-29$ & $7.11 \mathrm{E}-29$ \\
8 & $1.84 \mathrm{E}-28$ & $1.94 \mathrm{E}-26$ & $7.16 \mathrm{E}-29$ & $7.11 \mathrm{E}-29$ \\
9 & $1.04 \mathrm{E}-28$ & $1.74 \mathrm{E}-26$ & $7.635 \mathrm{E}-29$ & $8.36 \mathrm{E}-29$ \\
10 & $9.04 \mathrm{E}-28$ & $5.04 \mathrm{E}-26$ & $8.73763 \mathrm{E}-29$ & \\
\hline
\end{tabular}

\section{CONCLUSION}

A highly robust and quick fault diagnosis system in a three phase 7 level Multilevel inverter using the optimized RBFANN comprising meta-heuristic methods like PSO,GA,TSA and CSA. The single switch open fault for all the switches are trained using different algorithms and the results are discussed and tabulated. The fault identification after getting trained is tested in different condition and was found to be robust. According to the performance measure of MSE and RMSE the CSA algorithm performed better with the lowest MSE and RMSE and execution time was found less compared to other algorithms taken. Thus due to the reduced MSE and RMSE the CSA would be preferred for the hardware implementation.

\section{REFERENCES}

[1] T.G.Manjunath, Dr.AshokKusagur , "Fault Diagnosis and Reconfiguration of Multi level Inverter switch failure-A performance perspective", International Journal of Electrical and computer Engineering .Vol.6, No.6, December 2016, pp.2610-2620R. Arulmozhiyal and K. Baskaran, "Implementation of a Fuzzy PI Controller for Speed Control of Induction Motors Using FPGA," Journal of Power Electronics, vol. 10, pp. 65-71, 2010.

[2] T.G.Manjunath, Dr.AshokKusagur, "Multilevel Inverter Fault Diagnosis using optimized Radial Basis Neural Network-A Novel performance Enhancement", IEEE International Conference o Electrical, Electronics, communication, computer and optimization Techniques Systems (ICEECCOT), January 2017.

[3] T.G.Manjunath, Dr.AshokKusagur, "Performance Evaluation of Modified Genetic Algorithm over Genetic Algorithm Implementation on Fault Diagnosis of Cascaded Multilevel Inverter", IEEE International Conference on Conditioning Assessment Techniques in Electrical Systems (CATCON), December2015, CPRI, Bangalore.

[4] Kastha. D. and Bose. B. K. "Investigation of fault modes of voltage- fed inverter system for induction motor drive", IEEE Trans. Ind. Appl., vol. 30, no. 4, pp. 1028-1038, 1994.

[5] Mendes. A.M.S, Cardoso. A.J.M and Saraiva, E.S, “Voltage source inverter fault diagnosis in variable speed ac

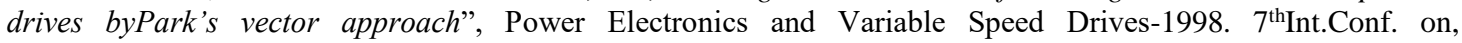
pp.538- 543.

[6] Mendes. A.M.S and Cardoso. A.J.M, “Voltage source inverter fault diagnosis in variable speed ac drives by the average current Park's vector approach", Electric Machines and Drives (IEMD)-1999, Int. Conf. on, pp. $704-706$.

[7] Bin Lu; Sharma, S.K., "A Literature Review of IGBT Fault Diagnostic and Protection Methods for Power Inverters", IEEE Trans. Ind. Appl., vol.45, no.5, pp.1770-1777, Sept. - Oct. 2009.

[8] S. Sedghi, A. Dastfan and A. Ahmadyfard, "Fault detection of a seven level modular multilevel inverter via voltage histogram and Neural Network", 8th Int. Conf. on Power Electronics - ECCE Asia- 2011, pp. 1005-1012.

[9] F. Pires, V. Foito, D.; Sousa, D.M. and Martins. J.F, “Fault detection on multilevel power converter based on mass centre of the voltage pattern", in Proc. Power Engineering, Energy and Electrical Drives (POWERENG)-2013, $4^{\text {th }}$ Int. Conf. on, pp. $576-581$

[10] Keswani, R.A, Suryawanshi. H. M. and Ballal, M.S, "Multi- resolution analysis for converter switch faults identification", Power Elec., IET, vol. 8, no. 5, pp. 783 - 792, May 2015.

[11] Keswani, R.A, Suryawanshi. H. M., Ballal, M.S and M. M. Renge, "Wavelet Modulus Maxima for Single Switch Open Fault in Multi- level Inverter", Electric Power Components and Systems, vol. 42, no. 9, pp. 889-900, 2014

[12] Vinothkumar, V and Muniraj, C., "Fault Diagnosis in H-Bridge Multilevel Inverter Drive Using Wavelet Transforms", Int. J. of Advanced Research in Electrical, Electronics and Instrumentation Engg,vol.2,no.4,Apr. 2013

[13] P. Lezana, R. Aguilera, and J. Rodriguez, "Fault detection on multicell converter based on output voltage frequency analysis”, IEEE Trans. Ind. Electron., vol. 56, no. 6, pp. 2275-2283, Jun. 2009.

[14] S. Khomfoi and L. Tolbert, "Fault diagnosis and reconfiguration for multilevel inverter drive using AI-based techniques, "IEEE Trans. Ind. Electron., vol. 54, no. 6, pp. 2954-2968, Dec. 2007.

[15] S. Khomfoi and L. M. Tolbert, "Fault diagnostic system for a multilevel inverters using a neural network," IEEE Trans. Power Electron., vol. 22, no. 3, pp. 1062-1069, May 2007. 
[16] Pawel StrumiUo and Wladyslaw Kaminski "Radial Basis Function Neural Networks: Theory and Applications" ,Neural Networks and Soft Computing pp 107-119

[17] Daniel Bratton and James Kennedy,"Defining a Standard for Particle Swarm Optimization", Proceedings of the 2007 IEEE Swarm Intelligence Symposium (SIS 2007)

[18] Xin-She Yang and Suash Deb, ” Cuckoo Search via Le' vy Flights “,2009 IEEE

[19] Sastry K., Goldberg D., Kendall G. (2005) Genetic Algorithms. In: Burke E.K., Kendall G. (eds) Search Methodologies. Springer, Boston, MA

[20] Wassim Jaziri, “Local Search Techniques: Focus on Tabu Search ,” Published by In-Teh,2008.

[21] Houshang Salimianet al, "Fault-Tolerant Operation of Three-Phase Cascaded H-Bridge Converters Using an Auxiliary Module", IEEE Transactions on Industrial Electronics (Volume: 64, Issue: 2, Feb. 2017 )

[22] June-Hee Lee, June-Seok Lee and Kyo-Beum Lee, "A fault detection method in cascaded H-bridge multilevel inverter", IEEE International Conference on Power and Energy,Nov.2016.

[23] Monikuntala Bhattacharya, Sankhadip Saha and Dibyendu Khan, "Wavelet based component fault detection in diode clamped multilevel inverter using probabilistic neural network", $2^{\text {nd }}$ IEEE International Conference for Convergence in Technology (I2CT), 2017.

\section{BIOGRAPHIES OF AUTHORS}
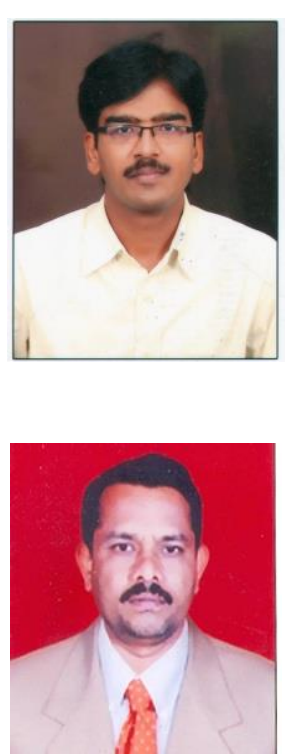

T.G. Manjunath. email ID: tgmnath@gmail.com, working as an Associate professor \& HOD at Sai Vidya Institute of Technology Bangalore, Karnataka. He received his B.E Degree from R.V. College of Engineering, Bangalore (Bangalore University) and Master Degree from U.V.C.E .Bangalore (Bangalore University) in the year 1999 and 2004 respectively. He worked in National Aerospace Laboratories (NAL) as project Associate \& having around 17 years of teaching experience in reputed Intitutions.He is currently pursuing his Doctoral research in Visveswaraya Technological University, Belgavi. His research includes in the field of Multi level Inverters, DC-DC Converters and ANN. He has published around 5 National /International journals and conferences in India \& Abroad.

Ashok Kusagur. email ID: ashok.kusagur@gmail.com, working as an Associate professor \& HOD at U.B.D.T. College of Engineering, Davanagere, Karnataka. He received his B.E Degree from Bapuji Institute of Engineering \& Technology, Davanagere (Kuvempu University) and Master Degree from PDA College of Engineering Gulbarga (Visveswaraya Technological University, Belgavi) in the year 1996 and 2001 respectively. He received his Ph.D. in the area "Design and implementation of Neuro -Fuzzy based speed control of Induction motor Drive by Space Vector Pulse width Modulation for Voltage source Inverters ${ }^{\text {eee }}$ from J.N.T.U Hyderabad in the year 2012. Under his supervision currently 8 research scholars are working. He has published 40 papers in various National /International journals and conferences in India \& Abroad. He is having around 20 years of teaching experience in reputed Institutions. His areas of interest are Fuzzy logic control of motor Drives \& Artificial Neural Network. 